which the British have perplexed the rest of the world for several centuries. It is therefore important that people elsewhere should recognize the function of the honours system. The driving force is the Civil Service, where permanent officials can count on a knighthood as a mark of seniority or even promise. In circumstances like these, it is right and proper that other public servants should be honoured, if only so that they should not be at a disadvantage in wringing money from a grasping Treasury. By this test, the Science Research Council should be stronger than last week, when its chairman was plain "Professor". It is less clear whether the future of the AEA will be helped now that its chairman, Dr J. M. Hill, is to be called Sir John; the cards are already stacked quite high. The irony is, of course, that those who most descrve these honours need them least as moral stiffening.

It would obviously be unfair, however, to keep knighthoods entirely within the public service, which explains why there is usually a fair sprinkling of other trades and professions--the occasional footballer, actor or even scientist. Academic scientists have done well out of the system, with 121 knighthoods among the 687 British Fellows of the Royal Society, not to mention two dames, the feminine equivalent, and eleven peerages. The correlation between the fellowship and the company of knights is indeed so high that those who have not yet been elected to the society may just as well regard that as the first step up the social ladder, just as those who have been fellows for some time may find it hard to persuade their wives to wait a little longer for the privileges which a knighthood brings, credit-worthiness at the grocer's, no doubt, chief among them.

To be sure, there are undoubtcdly some who decline to be thus honoured, and for as long as the British House of Lords persists, it will be smart to leap straight from the common hordes to the peerage, in the process limiting the confusion of public understanding by a single change of name. Lords Adrian, Blackett and Bowden are recent honourable precedents. The trouble, unfortunately, is that even this short cut to the top lends too much durability to the rituals of the Middle Ages. Now that it seems to be accepted that the House of Lords should not be appointed by heredity, it is high time that Lords were called $\mathrm{Mr}$ and there is even something to be said for a return to the bad old days when Mr Lloyd George used to exchange baronetcies for contributions to the funds of the Liberal Party. The sale of knighthoods could easily be made a keynesian deflationary device.

\section{CARBON FIBRES}

\section{Who makes What?}

IT now looks as if the House of Commons Select Com. mittce on Science and Technology will have its way about carbon fibres. A few weeks ago the committee was complaining that too little had been done to exploit this new technology, and asked in particular that some organization should build a plant capable of producing 100 tons of the material each year. Now it seems that several British companies are teetering on the edge of what looks very much like compliance. The most striking development is that Imperial Chemical Industries Ltd is having talks with the National Research Development Corporation about a manufacturing licence that would make it fourth in the carbon fibre club. As things stand, Courtaulds, the Morgan Crucible Company and Rolls-Royce Ltd have licences to manufacture the material. Much of the select committee's argument in favour of a bigger scale of production was the hope that bulk would bring cheaper material which would, in turn, stimulate the development of new uses.

Discussions between ICI and the NRDC began a week ago "with a view to obtaining a licence to manufacture carbon fibres throughout the world" after the NRDC had been told by the Ministry of Technology that none of the other licensees had plans to build a large-scale plant. It will now be for the NRDC to decide whether a fourth member of the club can be accommodated in the embryo market which now exists.

Rolls-Royce produces carbon fibres exclusively for its own use, principally in aircraft turbine blades. Both Courtaulds and Morgan Crucible consider that the demand for carbon fibres will increase only slowly, as new applications become practicable, and so they are arranging that production will be kept abreast of or just ahead of demand. Courtaulds has, however, let it be known that it is considering plans for a $£ 3$ million investment in a plant for producing 100 tons of carbon fibres a year. The NRDC is evidently hoping to find some anchorage in these shifting sands for a more reliable forward estimate, which is why the Programmes Analysis Unit, a joint venture of the Atomic Energy Authority and the Ministry of Technology, has been asked to make a survey of the prospects. With luck, the NRDC hopes to have the results three months from now, although it is doubtful whether this further delay will bring comfort to the Sclect Committee on Science and Technology.

Carbon fibres are made in Britain using a process developed by the Royal Aircraft Establishment in 1964. It consists of heating polyacrylonitrile, an organic polymer textile fibre, to leave a series of crystallites of pure carbon oriented along the length of the fibre. In 1961 the Osaka Industrial Research Institute of Japan developed a process for converting polyacrylonitrile to carbon fibres, but the process used by the RAE and patented in 1964 resulted in fibres with better properties. In its capacity as patent holder, NRDC awardcd manufacturing licences to the three firms already involved with carbon fibres. Courtaulds is supplying RAE with acrylic fibre and has experience of fibre handling, while the Morgan Crucible Company was brought in because of its knowledge of high temperature technology and previous experience of lowstrength carbon fibres. The Atomie Energy Research Establishment at Harwell produced carbon fibres for research and development and to study the production process with a view to lowering the cost of large-scale production. Harwell's trial design for a carbon fibre plant with a capacity of a million pounds a year showed that, if markets could be found, production 
costs should eventually fall to less than $£ 5 / \mathrm{lb}$. (NRDC has suggested a price range for the different types of fibre made with existing technology from about $£ 100$ to about $£ 5$ per pound.) Dr W. Marshall, the director of AERE, expects that if ICI does build a plant it will be of this sort of capacity. Talks between ICI and Harwell are already under way and Dr Marshall hopes that Harwell will be able to help with the design.

The next stage in producing a usable engineering material is to incorporate the carbon fibres into a suitable matrix, usually a plastic, but metals, ceramics and glasses can also be reinforced and the problem here is to ensure a good bond between the fibre and the matrix. Courtaulds has developed a process for treating the fibres so that they adhere strongly to resin and this is an important intermediate stage in the production of plastic composites. Fothergill and Harvey, a small advanced technology company in Lancashire, specializes in incorporating fibres into plastic and Morgan Crucible has just announced a bid to take over the company.

The likelihood that, in exchanging information with associated American firms on the production of carbon fibres, British companies might also pass on more general composite know-how was one of the chief fears expressed by the Select Committee in March. Each of the licensed British firms has an agreement with an American firm-Courtaulds with Hercules, Morgan with the Whittaker Corporation and Rolls-Royce with Lockheed-under which the American company can or will be able to manufacture carbon fibres in the United States. The idea is that this will make for a two-way flow of information, but the committee's fear was that it will speed up the manufacture of end products based on carbon fibre and that this will even further lengthen the lead that American firms already have in this field.

\section{MEDICINE}

\section{Agent 0114 Unmusked}

BaCteriological investigations have something in common with the better class of detective story, although the suspense is of a different order because real lives may be at stake. The report on the gastroenteritis outbreak in Manchester and Bury that killed thirty-nine babies early this year describes the rather elaborate measures that are necessary to deal efficiently with this kind of emergency (Report on Gastro-enteritis, Department of Health and Social Security). The hospitals concerned seem to have risen to the crisis in exemplary fashion, the only misfortune-understandable in the circumstances-being the possibility that the infection was transferred from one ward to another, probably by a member of staff or by equipment, in the Booth Hall Children's Hospital.

The four hospitals concerned in the outbreak were Booth Hall, Monsall and the Duchess of York Hospital, all in Manchester, and the general hospital in Bury. The number of gastro-enteritis cases among infants was not unusual for the time of the year but, after the first death in December, it became apparent during. January that the cases were particularly difficult to manage. After the second death on February 16, the hospital staff was thoroughly alarmed by the failure of the disease to respond to the usual method of treatment, which is to replace the infant's lost Aluids by intravenous feeding (antibiotics are a secondary method of attack). It was at this point that a new causal agent was suspected other than the usual pathogenic Escherichia coli, Salmonella and Shigella species. For various reasons it was thought that respiratory viruses or mycoplasma might be responsible and investigation along these lines was begun by Dr S. I. Jacobs, the consultant bacteriologist at Booth Hall and Monsall.

Dr A. G. Ironside, the medical director at Monsall, seems to have been among the first to suspect a new type of $E$. coli such as the strain that killed fifteen babies at Tees-side in 1967. On February 3 he wrote to the medical officer of health in Manchester, "For some time I have felt that the specific types of $E$. coli causing gastro-enteritis might be just as much of interest and concern to you as the other accepted intestinal pathogens, but in fact there is no formal notification of these cases". It was not until March 3, when two more babies had died, that it seemed worth following up this thought by sending samples to the Central Public Health Laboratory at Colindale.

The Colindale laboratory happens to possess the sera by which the 150 closely similar strains of $E$. coli can be identified. A fortnight after receiving the samples, the laboratory reported that two of the three babies from whom cultures were received possessed the $E$. coli strain 0114 . This was insufficient evidence to incriminate 0114 as the causal agent, but it was not until March 31 that new patients presented themselves. On that date, two babies previously discharged from Booth Hall were readmitted with gastro-enteritis and on April 2 the Colindale laboratory confirmed that both babies harboured $E$. coli 0114 . At this point, the difficult decision was taken to evacuate the Booth Hall wards for disinfection; admission of new patients had been stopped a fortnight before. When E. coli 0114 turned up in the Bury and Duchess of York Hospitals, which had had no previous contact with Booth Hall, it became fairly certain that the organism was the cause of the disease.

Faecal material from one of the earliest fatalities at Booth Hall had been stored for retrospective study and Dr Jacobs was able to show that the $E$. coli 0114 subsequently isolated from it was resistant to exactly the same antibiotics as the isolates made at the end of April. This indicates that the antibiotic treatment during the outbreak had no effect on the organism's pattern of resistance. Strains of $E$. coli 0114 isolated from the infants were resistant to the sulphonamides, tetracycline, chloramphenicol, neomycin, streptomycin, kanamycin, ampicillin, carbenicillin and cephaloridine. They were sensitive to gentamicin and colomycin and it is significant that of the ten infected infants in a ward at Booth Hall the three who survived had been receiving gentamicin or colomycin whereas the seven fatal cases had been treated with other antibiotics.

\section{FLUIDICS \\ Looking before Leuping}

THE infart technology of fluidics was given a cautious go-ahead by the British Hydromechanics Research Association in a report to the Minister of Technology. The report, based on a survey of fluidics in the United Kingdom, recommends that the ministry should support fluidics, mainly by direct assistance to a small 